\title{
Jon Juaristi y la concepción modernista de la nación, el nacionalismo y la tradición vascas (1985-1990). Un análisis etno-simbolista*
}

\author{
Jon Juaristi and the Conception of the Basque Nation, \\ Nationalism and Tradition (1985-1990). \\ An Ethno-Symbolic Approach
}

\author{
Ana Gandara Sorarrain \\ Universidad del País Vasco (UPV/EHU) \\ ana.gandara@ehu.eus \\ ORCID iD: https://orcid.org/0000-0002-9184-6225
}

\section{RESUMEN}

El primer objetivo de este trabajo es profundizar en la investigación de la diversidad en la concepción de los términos «tradición», «nación» $\mathrm{y}$ «nacionalismo» vascos en la obra poética de Jon Juaristi a lo largo de la segunda mitad de los años 80. Para ello, partiendo de la perspectiva etno-simbolista, sustraeremos las principales características - en clave modernista- y recursos - los lugares de memoria- que encontramos en los tres primeros poemarios de este autor. De tal forma, en este trabajo se presenta un primer paso para el reflejo de la diversidad de concepciones y percepciones que surgieron y se reflejaron en la literatura vasca a partir de la Transición en cuanto a la tradición, la nación y el nacionalismo vascos.

Palabras Clave: Jon Juaristi; etno-simbolismo; nación; nacionalismo; tradición; teoría modernista.

\section{ABSTRACT}

The aim of this paper is to research the conception diversity of the terms Basque «tradition», «nation» and «nationalism» in Jon Juaristi's poetical works during the late 80 s. In order to get into that diversity we will describe Jon Juaristi's first three poem books' characteristics about the three terms from an ethno-symbolic point of view: we will consider the influence of the modernist theory of nations and the specific use of memory places. In consequence, this work provides

* Esta publicación forma parte de los proyectos US17/10 (UPV/EHU) y FFI201784342-P (MINECO) que desarrolla el grupo de investigación MHLI (www.mhli.net), financiado por el Gobierno Vasco (IT 1047-16). 
a starting point in the description of the conception and perception about Basque tradition, nation, and nationalism since the Basque Transition.

Key words: Jon Juaristi; Ethno-symbolism; Nation; Nationalism; Tradition; Modernist theory.

\section{INTRODUCCIÓN}

En este trabajo analizaremos los tres primeros poemarios del escritor Jon Juaristi (Bilbao, 1951). Partiendo del estudio de las diferentes representaciones literarias de la concepción de la nación ${ }^{1}$ y la tradición vascas en Diario del poeta recién cansado ${ }^{2}$ (1985), Suma de varia intención ${ }^{3}$ (1987) y Arte de marear $^{4}$ (1988), presentaremos un análisis de los ejes teóricos que subyacen en el desarrollo de la concepción de estos dos términos.

Esta aproximación, por una parte, nos facilitará identificar los ejes fundamentales de este autor en la trayectoria conceptual y estilística de la nación y la tradición vascas en los años inmediatamente posteriores a la Transición y, por otra parte, aportará un ejemplo dentro de la diversidad de relatos y percepciones que surgieron desde mediados de los 70 hasta finales de los 80 .

Estas percepciones formaron parte del abanico conceptual que repercutió, en mayor o menor medida, en el desarrollo del sistema cultural vasco durante la época de la democracia. Este trabajo forma parte de un ejercicio más amplio, en el que analizamos la panorámica cultural y emocional en el País Vasco previo y posterior a la Transición.

En lo que respecta al presente trabajo, estudiaremos las diferentes representaciones conceptuales de la tradición, para lo cual nos centraremos en los aspectos relacionados con el nacionalismo, la nación y la identidad nacional vascas en el citado corpus. Haremos uso del correlato del predominio epistemológico de la historia social estructuralista en la investigación del nacionalismo - la teoría modernista o constructivista - y de algunas de las críticas que, a partir de la década de los 90 , se han hecho tanto a dicha perspectiva como al paradigma historicista en general: Anthony D. Smith y el etno-simbolismo, los lugares de memoria y Pierre Nora, respectivamente ${ }^{5}$.

${ }^{1}$ Seguimos a Anthony D. Smith en el uso general del término «nación» como ideal: «a named and self-defining human whose members cultivate shared memories, symbols, myths, traditions and values, inhabit and are attached to historic territories or 'homelands', create and disseminate a distinctive public culture, and observed customs and standardized laws» $(2009,29)$.

${ }^{2}$ En adelante, Diario.

${ }^{3}$ En adelante, Suma.

${ }^{4}$ En adelante, Arte.

${ }^{5}$ El cambio dado en la historia social estructuralista ha sido denominada «historia cultural» (Pablo et al. 2012, 23). 
El paradigma estructuralista se afianzó hacia 1970 con la orientación del foco analítico sobre los aspectos más materiales del proceso histórico (Pablo et al. 2012, 23; Gerard Noiriel, en Nora 2008, 8). No obstante, a partir de los años 90 se desarrollaron cambios respecto al prisma de dicho paradigma. Es entonces cuando empieza a surgir una nueva corriente basada en la historia cultural. Según ésta, las estructuras no son entidades objetivas, externas o ajenas a la actividad humana y determinantes desde la misma, sino de carácter contingente y maleable (Pablo et al. 2012, 23).

Es por ello que, a lo largo del escrito, analizaremos las posibles huellas de identidades y sentimientos de pertenencia confrontados y/o reflejados poéticamente, llegando a comprobar que la poética de J. Juaristi surge de las concepciones de «nación» $\mathrm{y}$ «tradición» entendidas desde el paradigma moderno.

Para ello, nos será necesario emplear las nuevas teorizaciones acerca del nacionalismo, ya que los cambios teóricos surgidos a partir de los 90 nos permiten analizar los signos de carácter modernista-construccionista desde una perspectiva distanciada del paradigma estructuralista, aportando nuevas explicaciones a fenómenos casi ignorados anteriormente. Entre los teóricos más significativos, las últimas aportaciones de los ya citados A. D. Smith y P. Nora reclaman más investigaciones sobre la relación -relegada hasta las últimas dos décadas- entre nacionalismo, simbolismo y memoria para la comprensión de las naciones, nacionalismos y sentimientos surgidos a partir de ellos.

El objetivo principal del presente trabajo de investigación delimita el uso de las teorías referidas a lo largo del escrito. Aunque con un objetivo mucho más sencillo de lo que sugiere el teórico A. D. Smith ${ }^{6}$, nos proponemos hacer un pequeño registro de algunas de las manifestaciones empíricas significativas de varias asunciones paradigmáticas, para poder así ir desgranando las diferentes formulaciones teóricas $\mathrm{y}$, sobre todo, manifestaciones poéticas que puedan ser reflejo de dimensiones culturales más amplias, a la par que significativas, del nacionalismo en los primeros e inmediatamente posteriores años a la Transición en el País Vasco.

La hipótesis principal de este trabajo parte, precisamente, de la influencia que pudiera tener la teoría modernista en la percepción de las naciones y los nacionalismos en los poemas de Jon Juaristi, pero parte del discurso es analizable desde un punto de vista más histórico-cultural y etno-simbolista. Es decir, si bien es cierto que en dichos poemarios se aplica la concepción modernista del nacionalismo, parte del discurso trabajado en los poemas es comprensible, precisamente, desde el enfoque de algunos críticos del paradigma moderno más allegados al enfoque de la historia cultural, de la concepción etno-simbolista y

${ }^{6}$ Smith propone, de entre las diferentes formas del etno-simbolismo, aquel que se centra en la naturaleza y el papel de las naciones en la historia: «en general mi aproximación se ha centrado en la forma en que vínculos étnicos anteriores, y a menudo premodernos, así como las etnias, han influido en las naciones y nacionalismos ulteriores» $(2000,393)$. 
de los partidarios de la investigación de la memoria libre de las ataduras reclusivas de la historiografía (José Rilla, en Nora 2008, 9).

\section{TEORÍA MODERNISTA BAJO REVISIÓN ETNO-SIMBOLISTA}

En los poemas de Jon Juaristi la concepción de la tradición, las naciones y los nacionalismos basada en el paradigma moderno se refleja de dos maneras. Por un lado, mediante la adopción de una de las mayores premisas modernistas: la concepción de las naciones, los nacionalismos y sus tradiciones como modernos -tanto cronológica como cualitativamente- y el carácter inventivo de dichas realidades. Por otro lado, la actitud respecto a los lugares de memoria comunes vascos descritos en Diario, Arte y Suma muestran ese mismo punto de vista: los lugares de memoria colectivos vascos reflejados en los poemas parten de las mismas premisas respecto a la nación y tradición vascas $\mathrm{y}$, a su vez, repercuten en el imaginario individual del poeta construido a partir de ese ideario.

\section{Nacionalismo moderno, tradición moderna}

Dentro del paradigma moderno, donde se tiende a dar preferencia a los factores reales, objetivos y materiales, la teoría modernista se muestra, en cuanto a la concepción de las naciones y de los nacionalismos, a dos niveles: el cronológico y el sociológico. Tres son los pilares de la teoría modernista de los nacionalismos: por una parte, se defiende que el nacionalismo -la ideología y el movimiento- es nuevo y reciente; por otra parte, las naciones son constructos noveles; por último, todos ellos son productos de la modernización -el movimiento global social de las sociedades hacia la modernidad (Smith 2009, 6)-.

La teoría modernista asume, por tanto, que la nación es una creación moderna de los últimos siglos: la élite nacionalista inventa una tradición (Hobsbawm y Ranger 1983) o bien construye una comunidad imaginada (Anderson 1983). En consecuencia, se niega todo tipo de antigüedad anterior al movimiento nacionalista asociado a la modernidad ${ }^{7}$ : «el nacionalismo es un producto de la modernidad, nada menos» (Smith 2004, 65). Esta teoría argumenta que sería la Revolución Francesa la que inauguró una nueva ideología, una forma de comunidad colectiva, un nuevo sistema político y un orden inter-estatal (ibíd.).

\footnotetext{
${ }^{7}$ Juaristi añadirá, años más tarde: «La melancolía nacionalista, como la melancolía imperial, es una variante de la melancolía derivada de la pérdida de la patria, pero hay una importante diferencia entre ambas. Al contrario que en el caso de los afligidos por la pérdida del Imperio, los nacionalistas no lloran una pérdida real. La nación no preexiste al nacionalismo» (1997, 31, la cursiva pertenece al texto original).
} 
En el caso de Juaristi, la variedad de modernismo que identificamos tanto en su obra ensayística como poética responde a la variante construccionista ${ }^{8}$. Tanto en El linaje de Aitor. La invención de la tradición vasca (1987) como en Literatura vasca (1987) y las posteriores El chimbo expiatorio (1994) y Sacra Némesis (1999) el autor desarrolla su discurso a partir de las ideas que predominan en dicha variante de modernismo. En lo que respecta a las obras contemporáneas a los poemarios a analizar, en El linaje de Aitor el autor se propuso describir «el proceso de invención de una entre las múltiples identidades vascas [...] la que comenzó a tener vigencia desde mediados del siglo XIX» (1998, 5-6); y el propio autor describió Literatura Vasca como «una Historia crítica de la literatura hispánica» $(1987 b, 9)$. Por otro lado, las posteriores El chimbo expiatorio y Sacra némesis partieron de la misma perspectiva, asumiendo que:

La nación, como ha observado Benedict Anderson, es una comunidad imaginada. Sin el desbordamiento de las percepciones sensoriales por el trabajo autónomo de la fantasía -o, en otras palabras, sin la hipertrofia de la medida del espíritu en detrimento de la medida de la vista- no cabría hablar de naciones (Juaristi 1999, 45).

Tal y como apuntaba José-Carlos Mainer en el prólogo a El chimbo expiatorio: «exhuma los restos olvidados de unos cuantos escritores bilbaínos [...] que, entre 1880 y 1936, inventaron una forma peculiar de costumbrismo y además un dialecto» (Juaristi 1999, 13).

En los poemarios concretos a los que hacemos referencia en este artículo, encontramos la misma correspondencia conceptual para con la variante construccionista. Por ello, en los siguientes párrafos, nos centraremos en analizar la temática modernista-construccionista detectada en Diario, Suma y Arte.

La característica modernista principal en los poemas del autor es la idea misma del construccionismo. En esta forma de modernismo se admite que las naciones y el nacionalismo son recientes; además, los dos teóricos más señalados de esta vertiente -los ya mencionados Eric Hobsbawm y Benedict Anderson- han destacado el carácter de construcción social en estos entes (Smith 2004, 66).

El aspecto construccionista de las naciones y los nacionalismos reflejado en las obras de Juaristi se corresponde al desarrollo que la reflexión identitaria sufrió en el País Vasco a partir de la Transición. Con el fin de la dictadura se profundizó en la reflexión sobre los diferentes niveles identitarios -el dilema identitario: la identidad nacional-estatal, la nacional-periférica y la supra-nacional'-, la amplitud de los mismos y su posible poder diluyente (Aguado 2010, 162): ser español, vasco, europeo.

${ }^{8}$ Para una descripción detallada de cada variante ver Smith 2000, capítulo 1; y para una descripción de las ideas comunes del paradigma moderno general, Smith 2004, 65-67.

${ }^{9}$ «La identidad europea no puede asentarse en la homogeneización cultural y lingüística de sus ciudadanos, un error en el que los Estados-nación han incurrido en demasiadas ocasiones al pretender aniquilar la diversidad existente en su interior a fin de crear un conjunto 
Además de la reflexión multi-focal de los niveles identitarios, tal y como apunta Iñaki Aldekoa:

No parece que, entre nosotros [la sociedad vasca], valores como la utopía/revolución hubieran sido cuestionados en los años ochenta. Más bien al contrario, ETA era la que venía catalizando dichos valores en el País Vasco, y mantuvo manu militari su discurso a lo largo de la década de los ochenta. No olvidemos que los ochenta fueron años de sangre y fuego. Y, aun cuando el tono intimidatorio de dicho discurso se fuera relajando a lo largo de los noventa, el mismo no quedaría desactivado por completo antes del 2000. El núcleo duro necesitó aún más tiempo, una década más, para ceder ante el acoso del Estado (2012, 11-12).

Tanto la reflexión de los diferentes niveles identitarios -la auto-visión (histórica) de la identidad vasca, española, europea- como el alto nivel de violencia vividos en los años 70-80 e inmediatamente anteriores, dieron paso en la década de los 80 a propuestas fundamentadas en el análisis ${ }^{10} \mathrm{y} / \mathrm{o}$, como en el caso de Jon Juaristi, la deconstrucción de algunos de los pilares identitarios sobre los que, históricamente, se habían fundamentado las identidades nacionalistas tales como la vasca.

Es precisamente en ese contexto donde se emplazan las obras poéticas que analizamos. En consecuencia, la concepción estilística y conceptual de la tradición vasca reflejada en los poemas de Jon Juaristi se suma a dicha reflexión identitaria, siempre a partir del ideario construccionista de las naciones y los nacionalismos.

En ese contexto, aun siendo constante el motivo de la invención de las tradiciones en los poemarios que analizamos, dos son los poemas más representativos en cuanto a esta idea: «Spoon River, Euskadi» (Suma, 28) y «En torno al casticismo» (Arte, 31-32). En el primer poema se hace referencia tanto a la ficción - «nuestros padres mintieron»- como a la falsificación -referencia al original Spoon River Anthology (1915)-:

¿Te preguntas, viajero, por qué hemos muerto jóvenes,

y por qué hemos matado tan estúpidamente?

Nuestros padres mintieron: eso es todo (Suma, 28).

homogéneo de ciudadanos. [...] En cambio, una identidad europea aún en ciernes depende de la conciencia compartida de pertenecer a un espacio político y económico definido por el capitalismo, el bienestar social, la democracia liberal, el respeto por los derechos humanos, la libertad y el Estado de derecho, la prosperidad y el progreso» (Guibernau 2009, 176).

10 «Los modelos más sugestivos que tenía entonces [con respecto a «cuáles fueron las mediaciones culturales que hicieron posible la sustitución de una autovisión a otra»] a la vista partían todos ellos del papel decisivo de la historiografía en la construcción de las identidades nacionales (así, por ejemplo, en los trabajos de José María Jover sobre el nacionalismo español y en la introducción de Diego Catalán a la nueva edición -1982- de Los españoles en la historia, de Menéndez Pidal). Pero ya Antonio Elorza había señalado con acierto que, en el caso vasco, la literatura de ficción histórica llena, en el XIX, el vacío de una historiografía inexistente» (Juaristi 1998, 6). 
Mediante la referencia a la obra de Edgar Lee Master (1868-1950), se correlaciona el carácter ficcional proyectado sobre la aldea desaparecida Spoon River en Euskadi y, a su vez, la rememoración de sus habitantes ya muertos con la de los antepasados en Euskadi. De tal forma, el autor crea un paralelismo evidente entre los habitantes desaparecidos de la ciudad imaginada y los antepasados -desaparecidos- de Euskadi -imaginada-.

En el segundo poema se ironiza sobre la antigüedad de la «tribu»:

En cuanto a mí, la tribu de que procedo, dicen, moraba ya en los flancos del alto Pirineo

allá cuando Caín sembraba cañamones,

y yo, que me lo creo,

no voy a mendigaros un plato de lentejas

ni un sitio junto al fuego. A ver quién se aventura, hermanos amadísimos, a negarme el derecho de primogenitura (Arte, 32).

Aparece también la invención de motivos cargados de simbolismo y sentimientos, tal y como los concibe Hobsbawm; para éste el elemento crucial es la invención de los signos parecidos a banderas e himnos (Hobsbawm y Ranger 1983, 11-12; Smith 2004, 219), al igual que en la escritura de Juaristi:

Y una raza me dio [la patria mía] que reza y canta ante el cántabro mar Cantos de Lelo ${ }^{11}$.

No merecía yo ventura tanta («Patria mía», Suma, 10).

Se entiende que detrás de las naciones existe una naturaleza artificial creada por una obra de ingeniería ideológica (Smith 2004, 227). En consecuencia, en El linaje de Aitor, Juaristi propone una deconstrucción de los referentes literarios vascos que han ido construyendo una de las múltiples identidades vascas, la identidad vasca moderna:

Mi proyecto [El linaje de Aitor] desembocó, por tanto, en una suerte de genealogía literaria de la formulación moderna de la identidad vasca. [...] creo que tal identidad, es decir, el imaginario en el que una colectividad se ha reconocido, ha

11 «Dos falsificaciones enriquecieron la leyenda vascocántabra. La primera, que Mañaricúa $[1973,160]$ cree invención de la apócrifa Crónica de Vizcaya de 1404, [...] La otra falsificación es el Canto de Lelo o Cantar de los Cántabros, recogido en la crónica de Juan Núñez de Ibargüen, y atribuido por Juan Carlos Guerra a un escritor vizcaíno del siglo XVI, Antón de Bedia [Guerra 1922, 130-133]. El autor, quienquiera que fuese, manipuló una cantilena tradicional (un lelo, en vasco), convirtiendo una retahíla sin sentido en la noticia de la muerte de un tal Lelo a manos de un tal Zara, y refiriéndose después, con acentos épicos, a la resistencia vascocántabra ante Roma y a dos caudillos vascos totalmente fabulosos, Lekobide y Uchín Tamayo» (Juaristi 1987b, 53-54). 
funcionado como una realidad histórica, como un vector, una fuerza que ha transformado en una dirección determinada la vieja sociedad tradicional (1998, 6-7).

En relación a la invención de la tradición y la identidad vascas modernas, en Diario, Suma y Arte predomina la actitud irónica, plasmada específicamente en las referencias concretas hechas a la nación, simbología y nacionalismo vascos. Este tono irónico pone de manifiesto la negatividad que le producen ciertos aspectos históricos, míticos y culturales de la comunidad vasca:

Es el nombre vulgar de un pez aún más vulgar:

de este linaje nocturno que cincela las aguas

junto a las cloacas. Tiempo sin duración.

$[\ldots]$

Premiosamente envejecemos, medidos por la acedia, contemplados

por los ojos de mármol de las gárgolas, cercados por campanas sumergidas. Terra marique potens ${ }^{12}$. Pueblo mío, encallado por siempre en tu lengua de piedra. Mi corazón, tan grave como un ancla de plomo se aferra a la carena de tu amor zozobrante. («Sermón de la atalaya de Lequeitio», Diario, 35-36)

Su pueblo -el nuestro- le irritaba (y no es difícil comprenderlo): huyó a las mugres intrahistóricas de las ciudades meserarias. («Invitation to a beheading», Diario, 49)

Luché por la veneranda lengua

[...]

En el altar sagrado de la Patria

sacrifiqué el pudor.

Mentí, como mentís ahora vosotros,

$[\ldots]$ vuestra sordera hereditaria, oh hijos putativos de Aitor («El gas de mi mechero», Suma, 30-31).

La negatividad proyectada en los referentes vascos se ve potenciada al ser reproducida en boca de una de las pocas referencias literarias clásicas de la literatura vasca libre de las ataduras del clericalismo ${ }^{13}$ :

${ }_{12}$ En el escudo de la villa de Lequeitio figura la leyenda «Reges debellavit horrenda cette subjecit terra marique potens Lequeitio» ('Lequeitio potente por tierra y por mar captura reyes y horrendos cetáceos').

${ }_{13}$ Nos referimos a Arnaud Oihenart (Mauleón, 1592-1667). En Suma, Juaristi tituló el cuarto poema «L'art poetique basque», haciendo referencia, sin duda, al homónimo L'art poetique basque de A. Oihenart, 1665, obra inédita hasta 1967 (Lafitte 1967). 


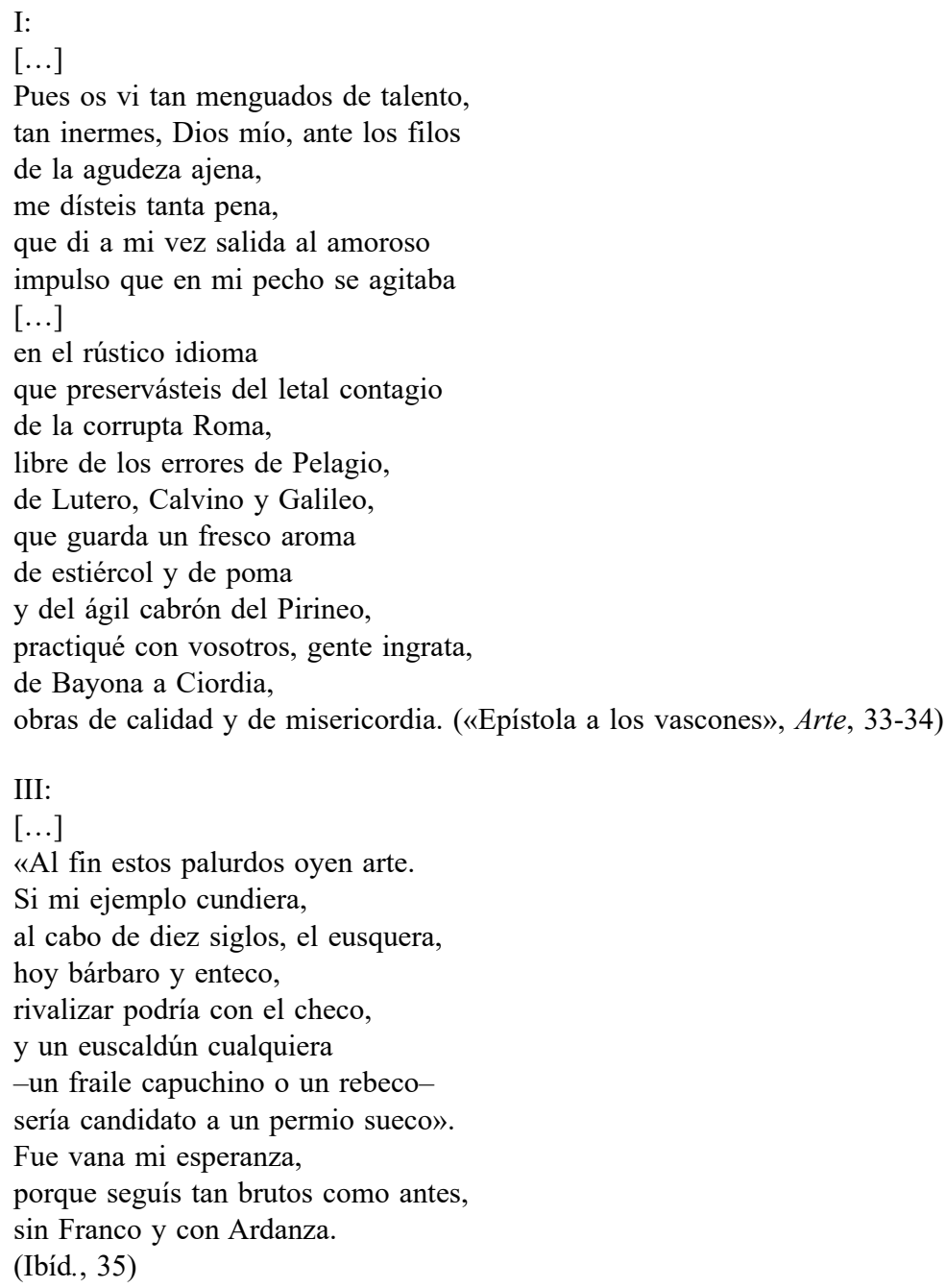

Tal y como se ve reflejado en el anterior poema, el pasado vasco se identifica con características arcaicas, rudas y poco provechosas para la vida intelectual.

Mirad bajo la piel de nuestros pueblos, allí donde el pasado se hace carne $\mathrm{y}$ es la sustancia del vivir el tedio.

Mirad más dentro aún: la fibra en que dormitan alcanforadas almas de curas y barberos soñando un horizonte de boinas escarlata («Ayer», Arte, 29). 
Se ironiza acerca de la figura del padre del nacionalismo histórico ${ }^{14}$ moderno vasco, Sabino Arana Goiri (Abando, 1865-1903), y la tradición que rememora éste junto a otro pastor:

Rompe la calma nemorosa y bruna

el dulce lamentar de dos pastores.

¿Sabes, Sabin, O tempora o mores,

que fuimos nobles incas en la puna? ${ }^{15}$ («Jardín de Abando», Diario, 47).

Con el «O tempora o mores» - ‘Oh tiempos, oh costumbres!'-, utilizado por Cicerón en la primera de la Catilinarias, se ironiza sobre el recuerdo de las costumbres de épocas pasadas.

En conclusión, podemos resumir que la concepción de la nación y el nacionalismo vascos que Jon Juaristi refleja en sus poemas responde a las directrices del paradigma moderno y, más concretamente, a la variante modernista-construccionista. En consecuencia, tanto la tradición vasca de finales del siglo XIX - asociada al movimiento nacionalista vasco- como los representantes de ésta se desaprueban.

Pero, ¿es posible que se haga referencia, en algún momento, a una tradición pre-moderna? ¿A una tradición desligada del concepto moderno de nacionalismo?

El vínculo irracional con respecto a la patria que acecha al poeta en Arte no coincide con los parámetros de la teoría modernista; es decir, dista de la racionalización de los parámetros modernistas-constructivistas con los que se deconstruye el ideario nacionalista moderno en las obras y pasajes ya mencionados.

Querrías, sin embargo, que la frágil ternura que todavía asocias a ciertas remembranzas no fuera solamente ilusorio desvío de la memoria al borde de su disolución («Reloj de melancólicos», Arte, 18).

14 Es decir, el Partido Nacionalista Vasco (EAJ-PNV), el que Juaristi identifica como parte de la raíz ideológica que engendra la identidad vasca moderna: «El énfasis en la diferencia entre vascos y españoles, característico de la autovisión decimonónica promovida por el regionalismo radical de los escritores fueristas y llevado al paroxismo por Sabino Arana Goiri, el fundador del Partido Nacionalista Vasco, que procede, en última instancia, de fuentes prusianas (Herder y Humboldt) y de las curiosas y fantásticas fabulaciones del teósofo francés Joseph-Augustin Chaho (1811-1858) y desplazó a un vasquismo - $\mathrm{o}$, mejor, 'vizcainismo', 'vascongadismo' o 'vasconavarrismo'- basado precisamente en la afirmación asimismo enfática de la identidad de lo vasco y de los español» $(1998,6)$.

${ }^{15}$ Claro guiño a la égloga primera de Garcilaso de la Vega, donde describía «El dulce lamentar de dos pastores, / Salicio juntamente y Nemoroso, / he de contar, sus quejas imitando» (1-3). 
Pero hay días que traen un pálpito siniestro:

ráfagas de certeza irrefragable

de que ya no eres otro que esta necia añoranza

retenida en los genes con rabia y con ternura («Por qué la quieres tango», Arte, 20).

Es decir, el vínculo emocional para con la patria reflejado, sobre todo, en Arte, tal y como argumentaremos en el siguiente apartado, parte de premisas y realidades que quedan fuera del alcance de los parámetros modernistas de las naciones y los nacionalismos.

La búsqueda de la razón de ser, motivo racional, de los mencionados sentimientos es el que se intenta encontrar en el viaje que se recoge en Arte (11-13). Es en ese viaje-retorno donde se hace mención sistemática de la palabra «matriz». La búsqueda es profunda y no parte del razonamiento modernista, sino de los sentimientos subjetivos y ataduras emocionales que esa misma teoría no explica, pues surge de la aparición de una realidad pre-moderna que la teoría modernista no contempla:

Pero eso debió ser muy al principio, porque hoy sólo me queda la extrañeza ante el desdén glacial con que miraban el cuchillo de Mayi, la de las manos rojas («Las ocas», Arte, 23).

Realidad libre de ideologías modernas, nacionalistas; unida a la vida tradicional de una patria, lejana, más bien abstracta, encarnada en ese lugar de memoria en el que se han convertido las mujeres de ese paisaje leitmotiv.

Se remonta así a sentimientos ancestrales, anteriores a los asociados al nacionalismo moderno, que perduran gracias a la longue durée. La tradición ligada a los sentimientos pre-modernos es una tradición diferente a la moderna $\mathrm{y}$, en este caso, está unida a sentimientos de pertenencia reflejados a través de una simbología más cercana a la figura femenina.

\section{Lectura etno-simbolista de la concepción modernista}

El etno-simbolismo ${ }^{16}$ nos brinda la oportunidad de entender el mundo interior de los miembros de una nación partiendo de los elementos simbólicos y de la dimensión subjetiva de los mismos (Smith 2009, 23). Ello hace posible que el foco no tenga por qué centrarse solamente en aquellas épocas que la teoría modernista analiza; es decir, el pasado reciente y el presente. Muy al contrario, se precisan y analizan también símbolos anteriores a la modernidad, los cuales son tremendamente importantes en la concepción de la tradición y

\footnotetext{
16 «Although it (the historical ethno-symbolism) offers no theory in the scientific sense, it seeks to provide some conceptual tolls for an alternative approach and research program for the study of nations and nationalism» (Smith 2009, 13).
} 
la nación-patria pre-modernas, tal y como veremos en las referencias hechas, especialmente, en los poemas de Arte.

En el caso de la poesía de Juaristi, es muy significativa la lectura que surge del prisma etno-simbolista, pues hace posible que detectemos y demos explicación a los sentimientos de arraigo hacia una patria vasca abstracta -y hacia lo vasco, siempre en relación a esa patria intemporal, en general- carente de cargas nacionalistas. Estos vínculos sentimentales reflejados en algunos de los poemas son causantes, a su vez, de un halo sombrío que se ve reflejado en el tiempo personal - presente- e histórico - pasado- que confluyen en Bilbao-Vinogrado. De tal forma, subrayando el rol de los recursos subjetivos y simbólicos en la motivación de las ideologías y acciones colectivas, «in doing so, they aim to enter the 'inner world' of the participants and understand their perceptions and visions» (Smith 2009, 16).

El punto de vista etno-simbolista es un intento de hacer justicia al debate sobre naciones y nacionalismos existente entre perenialistas y modernistas, estudiando las continuidades y discontinuidades de las memorias étnicas, los mitos, los símbolos, los valores y las tradiciones de comunidades culturalmente independientes (Smith 2000, 21). Los vínculos que representa esta perspectiva se fundamentan en la idea de que las naciones modernas se contextualizan en ciclos longue durée y en mitos étnicos, recuerdos, símbolos y tradiciones que mantienen ese vínculo entre el pasado y el presente:

For modernists, it is modernity that forms the matrix of nations. This entails both a chronological and a sociological evaluation. The time of 'modernity' is the recent past and the present; nothing before that matters. [...] Whereas for ethno-symbolists, such a radical truncation of history precludes any enquiry into long-term processes by which nations are formed and related to earlier cultural and political forms of society in the same area (Smith 2009, 16-17).

A través de los ciclos longue durée nos acercamos a naciones-comunidades y tradiciones lejanas, pre-modernas, que en su momento habrían servido de sustento - manipulado desde sus albores y transformado con el paso del tiempoa las ideologías nacionalistas en la modernidad. Parte de esa esencialidad de antaño, transformada en la modernidad, sería la que habría asegurado la fuerza y el éxito con el que los nacionalismos modernos irrumpieron y han seguido influyendo hasta la actualidad.

En la lectura que proponemos, combinamos esta perspectiva con la idea de los lugares de memoria desarrollados por Pierre Nora y varias decenas de investigadores en Les lieux de mémoire (Nora 1984-1992). La propuesta de Nora se enraíza en la idea de que la historia y la memoria se oponen:

Según Nora, memoria es vida encarnada en grupos, cambiante, $[\ldots]$ inconsciente de las deformaciones y manipulaciones, [...] mágica por su efectividad, sagrada. La historia en cambio es representación, reconstrucción, [...] destrucción del pasado tal cual es vivido y rememorado, traza consciente de la distancia entre el 
hoy y el ayer. La conciencia historiográfica desmonta esos mecanismos de la reconstrucción y la representación, dota al pasado de objetividad y a la historia de historicidad (José Rilla, en Nora 2008, 9).

Los lugares de memoria son el lugar de encuentro entre memoria e historia, donde existen «dos órdenes de realidades, lo tangible y lo simbólico, desmontados y explorados en sus elementos comunes» (José Rilla, en ibíd., 13). En lo que respecta a los poemarios de Jon Juaristi, concebimos estos lugares de memoria como recinto de la memoria para la conexión con la realidad tradicional del pasado -tanto pre-moderna como moderna- que sigue llamando y uniendo sentimentalmente - «me asediaban», escribe Juaristi (Diario, 19)-. No en vano, P. Nora propone el uso de estos lugares como únicos recintos mediante los cuales poder revivir la armonía entre historia y memoria en el mundo de hoy.

La combinación de la perspectiva etno-simbolista y los lugares de memoria como medio de resonancia de ese pasado lejano referencial -donde habitara la identidad nacional, no nacionalista- nos ofrece la oportunidad de entender el reflejo de ciertos apegos sentimentales; apegos que hemos podido identificar en los tres poemarios de la segunda mitad de los años 80 de Jon Juaristi: los apegos sentimentales mostrados en los tres libros y, aunque cuantitativamente menor, el apego memorístico de una tradición cultural ligada a la patria vasca. Una patria-nación pre-moderna, sin tintes nacionalistas.

Analizaremos la relación entre la identidad y el pasado referencial vascos que subyace en estos escritos, a la espera de mayores investigaciones que abarquen el corpus lírico del autor en su totalidad.

\section{LUGARES DE MEMORIA}

En este apartado trabajaremos con el segundo de los reflejos de los que consta la teoría modernista en los libros del escritor, analizando las dos categorías principales de lugares de memoria. No obstante, a medida que desgranemos el uso de los lugares de memoria, mencionaremos que en Bilbao-Vinogrado se crea un espacio donde tanto las experiencias individuales como las históricas se unen en sincronía, llegando a formar un loci personal: un cronotopo en el que se encierran recuerdos tanto colectivos como individuales.

Además, haciendo uso de la teoría etno-simbolista, presentaremos una posible explicación a la concepción modernista $-\mathrm{y}$ anti-nacionalista- de los lugares de memoria colectivos vascos en contraposición a las manifestaciones de la memoria identitaria que se reflejan en el binomio Bilbao-Vinogrado.

En cuanto a los lugares de memoria individuales, los versos son, en toda su extensión, el lugar de memoria más personal que Juaristi ofrece y utiliza. En Suma surge la escritura, la de los versos, como lugar de memoria en donde el poeta se adentra en la memoria del pueblo vasco: 


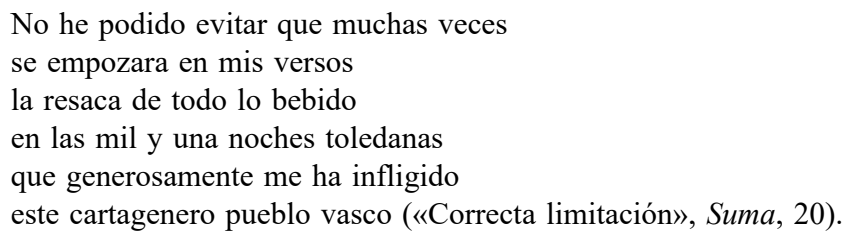

A partir de esta identificación, lo expresado y dicho en ese lugar de memoria se convierte en parte de la memoria individual de la voz poética.

Con respecto a los lugares de memoria colectivos vascos, mediante la negativización en las poesías de los lugares de memoria colectivos comunes vascos -lengua, tradición literaria, origen...-, el poeta consigue plasmar la esencia del paradigma moderno en dos órdenes. Por un lado, en el orden historiográfico -teórico-histórico-, mediante la demolición de los cimientos de los orígenes vascos, argumentándolos inventados, pues no se cree en la veracidad de lo que dichos lugares de memoria recogen y evocan. Por otro lado, en el orden estético, por medio de la contraposición e invalidación de los lugares de memoria vascos comúnmente canónicos en el ideario vasco moderno. Entre otros, motivos relacionados con la naturaleza (1), la lengua (2), personajes históricos del nacionalismo vasco (3) o la literatura (4):

(1)

el escudo del Gorbea que algún chusco llamó gigante («Mox nox», Arte, 16).

(2)

pueblo vasco de lengua envenenada,

$[\ldots]$

Jamás, sobre esta tierra de cristianos

volveré a hablar en vuestro ingrato euskera («Euskadi», Diario,52).

nuestra dulce lingua nauarrorum («L'Art Poetique Basque», Suma, 11).

es notable que lo dijera en bable («Vino grado revisited», Suma, 27).

(3)

La figura de Sabino Arana Goiri en «Jardín de Abando» y «El sitío de Bilbao» (Diario, 47, 54).

(4)

os supongo avezados de antiguo a la engañosa

ceremonia de sombras que solemos

llamar Literatura («Alter Bilbao mond», Suma, 12).

En los tres libros de poemas que tenemos entre manos están presentes los lugares de memoria vascos comunes, pero la relación con el recuerdo y con lo recordado es ligeramente diferente en los poemarios. Los lugares de memoria que se aprecian en los dos primeros libros, aunque parecidos en referencias, 
difieren de los que nos encontramos en Arte. La diferencia principal reside en la actitud para con estos referentes, junto con el uso que se hace de ellos.

Tanto en Diario como en Suma la evocación de los lugares de memoria se centra en gran medida en negar todo sentido cercano a la ideología nacionalista vasca en sus diferentes vertientes: la percepción de la lengua, la honorificencia del pasado, la invención de la tradición moderna... proyectan una asociación negativa para con la ideología, el ideario y el movimiento nacionalistas. Por consiguiente, el reflejo ideológico de la teoría modernista respecto a la nación y al nacionalismo resulta ser uno de los focos del uso de los lugares de memoria. No obstante, la intensidad negativa es mucho mayor en Suma, donde los supuestos ideológicos que la teoría modernista establece son llevados hasta el extremo en el lenguaje poético haciendo un uso más marcado de la ironía ${ }^{17}$ («Vino Grado revisited», Suma, 27).

Sin embargo, para poder entender el apego hacia una posible patria pre-moderna es importante reparar en el binomio Bilbao-Vinogrado. Este loci surge como lugar de memoria personal en el que confluyen el tiempo personal y el colectivo; la voz poética crea un cronotopo de corte personal y, a su vez, con raíces colectivas. Tanto las experiencias personales como la realidad bilbaína que se dibujan en este cronotopo actúan como caja de resonancia de los sentimientos generados por la patria vasca no-nacionalista y el nacionalismo vasco.

La capacidad proyectiva de este cronotopo se adhiere a la realidad no-moderna de la patria vasca que la voz poética siente evocada. En Arte, especialmente, Juaristi vuelve al espacio de la patria, identificado en el imaginario Bilbao-Vinogrado - «he remontado el río» (11), «volví a tu ría negra» (21)-, en busca de respuestas a los sentimientos de arraigo, tal y como dice en «Última lección» (11-13) ${ }^{18}$. El vínculo irracional que acecha al poeta se refleja con claridad en los poemas «Por qué la quieres tango» (19-20) y «Reloj de melancólicos» (18). En éstos, los sentimientos a los que hace referencia el arraigo irracional a la identidad-patria no son canalizados ni por medio de los parámetros de la teoría modernista ni por medio de la racionalización de los argumentos que dicha teoría defiende.

Querrías, sin embargo, que la frágil ternura que todavía asocias a ciertas remembranzas no fuera solamente ilusorio desvío de la memoria al borde de su disolución (Arte, 18).

Pero hay días que traen un pálpito siniestro: ráfagas de certeza irrefragable

${ }^{17}$ Queremos dar a entender que, así como Suma es más irónico que Diario, Arte recoge la ironía más afilada en «La epístola a los vascones». En el poema, se reproducen reflexiones imaginarias que la figura literaria tradicional Arnaud Oihenart hiciera sobre los vascos (ver las estrofas reproducidas del poema en el apartado primero).

18 «He remontado el río, / buscando el hontanar / de mi daño. / Te ofrezco este cuaderno / de viaje» (Arte, 12). 
de que ya no eres otro que esta necia añoranza

retenida en los genes con rabia y con ternura (Arte, 20).

La búsqueda de la razón de ser de ese arraigo emocional es, precisamente, la que se intenta encontrar en el viaje realizado en Arte. En consecuencia, los lugares de memoria y el propio Bilbao-Vinogrado cumplen una función diferente de la que tenían en las anteriores obras poéticas; la relación de confluencia que guarda el cronotopo Bilbao-Vinogrado con la búsqueda del motivo racional de los sentimientos de pertenencia brotados es más profunda.

Dando un significado global al conjunto de los trabajos, Arte es el diario de viaje del poeta que regresa a la lejana patria vasca («partiré un día», Diario, 18; «me voy», Suma, 24; «pronto me iré de aquí», Suma, 47). Así, los recuerdos se vuelven una reflexión constante, esta vez en diálogo con los sentimientos que llevan al poeta a acercarse a los lugares de memoria.

Si Pierre Nora propone el uso de los lugares de memoria como únicos recintos mediante los cuales poder revivir la memoria en el mundo de hoy, el estudio de los poemas de Jon Juaristi nos hace reflexionar sobre la relación entre identidad y pasado referencial que subyace en sus escritos. Cuanto menos, cabe destacar la dialéctica que predomina entre identidad vasco-española no nacionalista y los lugares de memoria negativamente percibidos en los versos, a su vez reunidos en el cronotopo Bilbao-Vinogrado, en confluencia con la memoria individual de la voz poética.

Precisamente esa negatividad proyectada es una de las evidencias para poder argumentar que Juaristi es un escritor -no solo escritor poético, sino historiográfico, como demuestran El linaje de Aitor, Literatura vasca, El chimbo expiatorio, El bucle melancólico y Sacra Némesis- adherido a la relación pasado-individuo que presupone la teoría modernista. En ese contexto, es fundamental la función que adquiere Bilbao-Vinogrado en la canalización de los sentimientos individuales con respecto a la patria vasca de la mano de retazos de la memoria colectiva. En Arte, Bilbao-Vinogrado se convierte en lugar de memoria individual donde surgen tanto el recuerdo de la memoria colectiva -por medio de lugares de memoria- como el de la memoria individual; o, igualmente, la trayectoria individual y la experiencia histórica (Díaz de Castro 2002, 21).

Tal y como explicaba Bajtin en cuanto al cronotopo artístico literario, «los elementos del tiempo se revelan en el espacio, y el espacio es entendido y medido a través del tiempo» $(1989,238)$; en Bilbao-Vinogrado son las vivencias, los recuerdos y las emociones personales los que canalizan la percepción de los recuerdos tanto personales como colectivos.

Por ello, el autor vuelve a ese lugar en busca de respuesta a los sentimientos de apego surgidos:

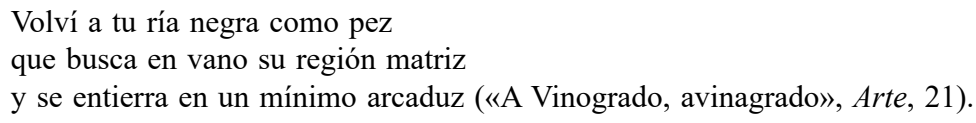


Para ello, los lugares de memoria son activados por medio de la(s) llamada(s) -sonidos, voces, luces- que reclaman la atención hacia ese pasado conectado con la tradición e identidad vascas en las cuales Juaristi identifica su origen:

- Luz, llama no extinta:

Vidrio abisal ¿qué es esa

luminaria imprecisa?

Llama malva no extinta

desciende con nosotros («Katabasis», Diario, 41).

- Sonidos, ecos del pasado:

«But at my back I always hear

Time's winged

chariot hurrying near ... Andrew Marvell»

$[\ldots]$

Y detrás de la puerta son

las risas de las estudiantes

como el piafar de yeguas uncidas

al carro aquel que oyera Marvell («Mox nox», Arte, 16-17).

Mirad más dentro aún: la fibra en que dormitan

alcanforadas almas de curas y barberos

soñando un horizonte de boinas escarlata.

Rumor de fronda llega del fondo de su sueño («Ayer», Arte, 29).

- Llamadas-voces que requieren al autor insistentemente:

Si un día de olvidarte fui capaz,

me llamaste otra vez con otra voz («A Vinogrado, avinagrado», Arte, 21).

Las «voces» ${ }^{19}$ han formado parte de la obra de Juaristi a lo largo del tiempo. Pero, de entre las obras poéticas de la segunda mitad de los años 80 , parecen cobrar mayor intensidad en Arte, en la obra que explora poéticamente con mayor intensidad los sentimientos de pertenencia para con la patria vasca.

\section{CONCLUSIONES}

Aunque Jon Juaristi ha trabajado la historiografía de la identidad vasca moderna desde la hasta hace poco predominante historia social estructuralista dando importancia a la investigación científica (1987a, 1987b, 1994, 1999), la

19 «no podemos vivir sordos a las voces ancestrales. Si nos empeñamos en desoírlas, volverán con más fuerza que nunca, vindicativas y destructoras» (Juaristi 1999, 18). 
naturaleza de los poemas analizados nos indica que su práctica poética en los primeros tres poemarios está más ligada a la memoria.

Precisamente los lugares de memoria se convierten en el «nuevo» nexo necesario para la unión, debilitada ya, entre memoria e historia. La peculiaridad de la poética de Juaristi radica en que el autor refleja dos actitudes hacia esos lugares de memoria: a la vez que niega aquellos lugares colectivos vascos como reflejo de la perspectiva en la investigación del nacionalismo a través de la teoría modernista-constructivista, crea un espacio en el que memoria-vivencia individual e historia se cruzan en un mismo tiempo múltiple: Bilbao-Vinogrado. La profundidad referencial y asociativa de Bilbao-Vinogrado la convierten en la patria querida y añorada, desasosegante y siniestra-el humheimlich freudiano-.

La relación entre memoria e historia que se establece en Diario, Suma y Arte es muy actual: parte de la esencia de la escritura del autor está en la simultaneidad del tiempo personal e histórico, conformando una realidad heterosincrónica en la que temporalidades heterogéneas conviven en un mismo espacio (Cruces 1997, 55). Bilbao-Vinogrado es un espacio donde el pasado y el presente se fusionan y reviven, rememoran:

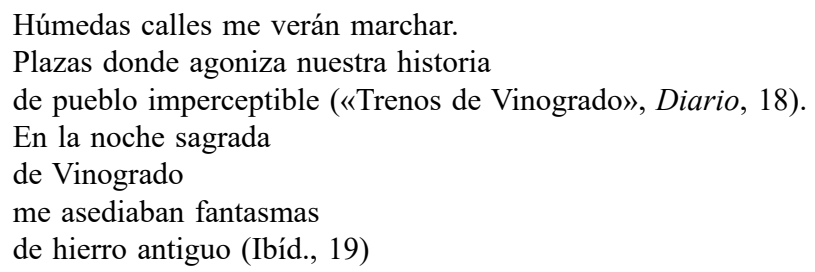

Por ello, afirmamos que en los poemas de Juaristi los lugares de memoria colectivos vascos se convierten en lugares para la memoria donde encontrar espacios en los cuales cristalizar y asegurar el apego sentimental de la comunidad negada.

Además, son dos las posibles tradiciones identificadas en los poemas: la pre-moderna, anterior al cambio moderno del XIX y la moderna, desarrollada a partir de la ideología surgida del cambio a la modernidad. El paradigma estructuralista ofreció un distanciamiento en la concepción del nacionalismo moderno; solo la falta de identificación absoluta hace posible la crítica al nacionalismo que se describe a partir de ella.

Juaristi, seguidor de la perspectiva modernista-constructivista, asume un distanciamiento implícito hacia lo criticado y deconstruido, que más tarde se ve truncado con los sentimientos de arraigo hacia su tierra y el recuerdo de la tradición pre-moderna. Ésta está unida a sentimientos anteriores a la concepción del nacionalismo como ideología. Simbolismo que ha perdurado en la resonancia que los lugares de memoria representan, aun débilmente, en los poemas de Jon Juaristi. No obstante, la única presencia de esta tradición hace imposible 
un mayor esclarecimiento de cómo, por qué y de qué manera se vive el recuerdo leitmotiv de la tradición pre-moderna.

La teoría modernista no da respuestas a todos los sentimientos encontrados que se reflejan en Diario del poeta recién cansado, Suma de varia intención y Arte de marear. Hace falta otra aproximación para lograr entenderlos en su conjunto. Por ello, hemos intentado en el presente escrito trabajar los poemas bajo un prisma diferente: la historia cultural. Sirva pues este primer ensayo como el inicio de más estudios sobre la historia cultural de las naciones y las vivencias personales de las mismas. Estudios que pueden ayudarnos a entender mejor la diversidad y riqueza de percepciones identitarias que surgieron a partir de la Transición.

\section{BIBLIOGRAFÍA CITADA}

Aguado, Txetxu. 2010. Tiempos de ausencias y vacios: Escrituras de memoria e identidad. Bilbao: Universidad de Deusto.

Aldekoa, Iñaki. 2012. «Una mirada a la literatura vasca y a la postmodernidad». Oihenart 27, 9-25.

Anderson, Benedict. 1983. Imagined Communities: Reflections on the Origin and Spread of Nationalism. Londres: Verso.

Bajtin, Mijail. 1989. Teoría y estética de la novela. Traducción de Helena Kriúkova y Vicente Cazcarra. Madrid: Taurus.

Cruces, Francisco. 1997. «Desbordamientos. Cronotopías en la localidad tardo-moderna». Política y Sociedad 25, 45-58.

Díaz de Castro, Francisco. 2002. Vidas pensadas: poetas del fin de siglo. Sevilla: Renacimiento.

Guerra, Juan Carlos. 1922. «Los cantares antiguos del Euskera». EA 12, 130-133.

Guibernau, Montserrat. 2009. La identidad de las naciones. Barcelona: Ariel.

Hobsbawm, Eric y Terence O. Ranger, eds. 1983. The Invention of Tradition. Cambridge: Cambridge Univ. Press.

Juaristi, Jon. 1985. Diario del poeta recién cansado. Pamplona: Pamiela.

Juaristi, Jon. 1987a. El linaje de Aitor: La invención de la tradición vasca. Madrid: Taurus. Juaristi, Jon. 1987b. Literatura vasca. Madrid: Taurus.

Juaristi, Jon. 1987c. Suma de varia intención. Pamplona: Pamiela.

Juaristi, Jon. 1988. Arte de marear. Madrid: Hiperión.

Juaristi, Jon. 1994. El chimbo expiatorio. Bilbao: Tilo.

Juaristi, Jon. 1997. El bucle melancólico: Historias de Nacionalistas Vascos. Madrid: Espasa. Juaristi, Jon. 1998. «Prólogo a la segunda edición». En El linaje de Aitor. La invención de la tradición vasca, 3-9. Madrid: Taurus.

Juaristi, Jon. 1999. Sacra Némesis: Nuevas Historias de Nacionalistas Vascos. Madrid: Espasa.

Lafitte, Pierre ed. 1967. «L'art poétique basque (Un inédit d'Arnaud d'Oyhénart)». Gure Herria Octubre: 195-234.

Masters, Edgar Lee. 1915. Spoon River Anthology. EEUU: Macmillan \& Co.

Nora, Pierre, dir. 1984-1992. Les lieux de mémoire. 3 vols. París: Gallimard. 
Nora, Pierre, dir. 2008. Pierre Nora en Les lieux de mémoire. Traducción de Laura Masello. Montevideo: Ediciones Trilce.

Pablo, Santiago de, José Luis de la Granja, Ludger Mees y Jesús Casquete, coords. 2012. Diccionario ilustrado de símbolos del nacionalismo vasco. Madrid: Tecnos.

Smith, Anthony David. 2000. Nacionalismo y Modernidad: Un estudio crítico de las teorías recientes sobre naciones y nacionalismo. Traducción de Sandra Chaparro. Madrid: Istmo.

Smith, Anthony David. 2004. Nacionalismo: Teoría, ideología e historia. Traducción de Olaf Bernárdez Cabello. Madrid: Alianza Editorial.

Smith, Anthony David. 2009. Ethno-symbolism and Nationalism: A Cultural Approach. Nueva York: Routledge.

Fecha de recepción: 05 de abril de 2017.

Fecha de aceptación: 05 de septiembre de 2017. 